\title{
SINTESA LAPISAN NIKEL (Ni) PADA PERMUKAAN BAJA DENGAN METODE ELEKTRODEPOSISI DENGAN PENAMBAHAN INHIBITOR EKSTRAK KULIT BUAH KAKAO (THEOBROMA CACAO)
}

\author{
Yuli Yetri", Silva Azaria Mahaputri*, Dahyunir Dahlan* \\ \#Jurusan Teknik Mesin, Politeknik Negeri Padang, Kampus Limau Manis, \\ Padang, 25163 \\ *Jurusan Fisika, Fakultas Matematika Dan Ilmu Pengetahuan Alam, \\ Universitas Andalas, Kampus Limau Manis, Padang, 25163 \\ E-mail: yuliyetriyetri@gmail.com
}

\begin{abstract}
Abstrak
Telah dilakukan proses elektrodeposisi lapisan $\mathrm{Ni}$ diatas subtrat baja dengan menggunakan larutan 0,5 $\mathrm{M}$ $\mathrm{NiSO}_{4} .6 \mathrm{H}_{2} \mathrm{O}, \mathrm{H}_{3} \mathrm{BO}_{3}$ dengan penambahan inhibitor ekstrak kulit buah kakao. Pada penelitian ini dilakukan variasi tegangan elektrodeposisi 1, 2, 3 dan $4 \mathrm{~V}$. Sementara variasi konsentrasi inhibitor ekstrak kulit buah kakao dilakukan dengan variasi konsentrasi $1 \%$ dan $2 \%$. Waktu elektrodeposisi dilakukan selama 25 menit untuk setiap sampelnya. Terdapat perbedaan morfologi pada baja sebelum dan setelah dielektrodeposisi. Peningkatan tegangan maka hasil dari deposisi terlihat semakin tebal. Dengan melakukan variasi konsentrasi dan variasi tegangan elektrodeposisi, didapatkan konsentrasi yang baik yaitu dengan konsentrasi $1 \%$ dengan tegangan 3 Volt. Penambahan inhibitor ekstrak kulit buah kakao membuat morfologi permukaan baja menjadi lebih halus dan lebih merata.
\end{abstract}

Kata Kunci: Baja, Elektrodeposisi, $\mathrm{NiSO}_{4}$, Inhibitor, Ekstrak Kulit Buah Kakao

\begin{abstract}
A process of $\mathrm{Ni}$ layer electrodeposition has been performed on a steel substrate using a $0.5 \mathrm{M} \mathrm{NiSO}_{4} .6 \mathrm{H}_{2} \mathrm{O}_{\text {, }}$ $\mathrm{H}_{3} \mathrm{BO}_{3}$ solution with the addition of a extract inhibitor cacao peels. In this research, there are variations of electrodeposition voltage 1, 2, 3 and $4 \mathrm{~V}$. While the variation of extract inhibitor cacao peels concentration is done with variation of concentration $1 \%$ and $2 \%$. The electrodeposition time was carried out for 25 minutes for each sample. There are morphological differences in steel before and after electrodeposition. Increased voltage then the results of the deposition looks more and more thick. By varying the concentration and variation of the electrodeposition voltage, a good concentration of $1 \%$ with 3 volts is obtained. The addition of a extract inhibitor cacao peels shell extract inhibitors makes the surface morphology of the steel becomes smoother and more evenly distributed.
\end{abstract}

Keyword: Steel, Electrodeposition, $\mathrm{NiSO}_{4}$, Inhibitor, Cacao Peels Extract

\section{PENDAHULUAN}

Baja telah banyak digunakan dibidang industri karena material ini kuat, mudah ditempa, mudah teroksidasi, daya hantar listrik dan panas yang baik. Beberapa aplikasi penggunaan baja adalah seperti pipa pengaliran minyak lepas pantai, konstruksi jembatan, bangunan, kerangka kendaraan. Tetapi baja sangat mudah teroksidasi, karena berinteraksi langsung dengan lingkungan sekitarnya dan mengakibatkan terjadinya korosi. Korosi tidak hanya merugikan manusia dan lingkungan dan secara ekonomis tetapi juga mengakibatkan pemborosan biaya dan kerugian ekonomi yang sangat besar ${ }^{[1]}$ bahkan dapat mengancam keselamatan manusia ${ }^{[2]}$. Korosi adalah proses kerusakkan akibat adanya reaksi kimia antara logam atau paduannya dengan lingkunganya ${ }^{[3]}$. Korosi pada logam merupakan proses reaksi reduksi dan oksidasi kimia atau elektrokimia yang menyebabkan transfer elektron dari baja ke lingkungan sehingga terjadi perubahan bilangan 
oksidasi logam dari nol menjadi bermuatan positif [4].

Untuk mencegah logam tersebut dari kerusakkan dan tampilannya tetap bagus telah dilakukan berbagai cara untuk meminimalisir terjadinya korosi. Dengan cara membersihkan, mencat, atau melapisi permukaannya. Cara yang lebih efisien dan mudah dilakukan untuk melapisi permukaan baja yaitu dengan cara metode elektrodeposisi. Elektrodeposisi adalah melapisi permukaan baja dengan logam lainnya dengan menggunakan bahan larutan elektrolit ${ }^{[5]}$, disini digunakan $\mathrm{NiSO}_{4}$. Adapun cara lain yang dapat digunakan untuk sebagai pelapis permukaan yaitu dengan menambahkan larutan inhibitor, dimana larutan inhibitor ini untuk memperlambat laju korosinya. Ada banyak inhibitor yang bisa kita dapatkan, ada inhibitor organik dan anorganik. Inhibitor anorganik lebih berbahaya karena termasuk senyawa kimia serta relatif lebih mahal ${ }^{[6]}$. Sedangkan inhibitor organik kita bisa mendapatkan dari alam dan relatif lebih murah dan mudah dilakukan. Jadi kita bisa memanfaatkan senyawasenyawa organik yang terdapat di alam sebagai inhibitor, dimana bahan- bahan alam yang kita pilih yaitu bahan alam yang mengandung zat tanin, yang dapat manghambat terjadinya proses korosi.

Dari beberapa penelitian yang telah dilakukan dengan menggunakan tumbuhan sebagai contoh adalah inhibitor getah pinus, ekstrak gambir dan ekstrak kopi ${ }^{[5]}$, inhibitor ekstrak nenas ${ }^{[4]}$, ekstrak sambiloto $^{[7]}$, inhibitor ekstrak kacang merah ${ }^{[8]}$, ekstrak aningeria robusta ${ }^{[9]}$, ekstrak camellia sinensis ${ }^{[7]}$, ekstrak daun $\operatorname{sirsak}^{[10]}$, ekstrak daun bayam merah $^{[9],}$ ekstrak kulit buah kakao ${ }^{[3,10,1,2]}$.

Telah dilakukan penelitian inhibisi korosi dan pemulihan sifat mekanik baja lunak menggunakan ekstrak kulit buah kakao (Theobroma cacao) dalam media asam ${ }^{[10,1,2]}$. Telah dilakukan juga penelitian tentang perilaku korosi inhibitor yang ramah lingkungan dari ekstrak kulit buah kakao untuk baja ringan dalam media korosif $\mathrm{NaCl} 1.5 \mathrm{M}^{[2]}$.

Maka penelitian ini memanfaatkan kulit buah kakao sebagai inhibitor yang akan dilapisi kepermukaan baja dengan menggunakan metode elektrodeposisi dengan penambahan zat $\mathrm{NiSO}_{4}$.

\section{METODE DAN BAHAN}

1. Pembuatan Larutan Elektrolit

Larutan elektrolit yang digunakan adalah larutan $\mathrm{NiSO}_{4}$ yang dibuat dengan cara menimbang zat $\mathrm{NiSO}_{4}$ sebanyak 20 gram dan ditambahkan 3 gram $\mathrm{H}_{3} \mathrm{BO}_{3}$ serta dilarutkan dalam $200 \mathrm{~mL}$ aqudest. Kemudian larutan tersebut diaduk dengan menggunakan magnetic stirrer selama 30 menit pada suhu kamar.

\section{Kakao}

2. Pembuatan Ekstrak Kulit Buah

Kulit buah kakao yang didapatkan diiris tipistipis dan dikering anginkan selama 14 hari, kemudian setelah kering digerinda dengan mesin gerinda. Kulit buah kakao hasil dari gerinda dimaserasi dengan menggunakan metanol $70 \%$ selama 5 hari, setelah itu kita saring dan dilakukan pemekatan dengan menggunakan vakum evapolator. Hasil dari vakum evapolator kita dapatkan ekstrak pekat kulit buah kakao. Hasil dari ekstrak pekat kulit buah kakao kita buat larutan induk yang nanti akan dilarutankan menjadi variasi konsentrasi.

\section{Proses Elektrodeposisi}

Proses elektrodeposisi dilakukan dengan melarutakan $5 \mathrm{ml}$ larutan $\mathrm{NiSO}_{4}$ dan $5 \mathrm{ml}$ larutan ekstrak kulit buah kakao. Larutan gabungan tersebut di masukan kedalam alat elekrodeposisi. Dilakukan variasi tegangan 1 volt sampai 5 volt, dan juga dilakukan variasi konsentrasi dengan konsntrasi inhibitor ekstrak kulit buah kakao $1 \%$ dan 2\% dan dengan tanpa adanya penambahan inhibitor ekstrak kulit buah kakao.

\section{HASIL DAN PEMBAHASAN}

A. Karakterisasi Permukaan Dengan Mikroskop Optik

Karakterisasi permukaan dilihat dengan menggunakan Mikroskop optik, dimana seluruh hasil dari varisi tegangan dan penambahan inhibitor ekstrak kulit buah kakao dilihat dengan menggunakan mikroskop optik. Hasil dari mikroskop optik dapat dilihat pada Gambar 1.

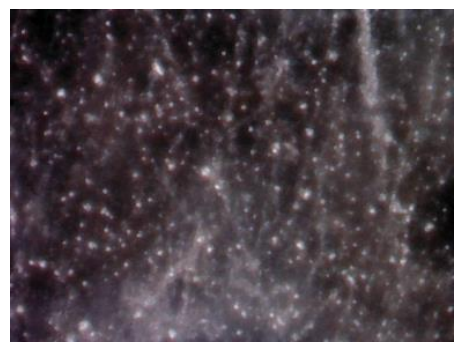

(a)

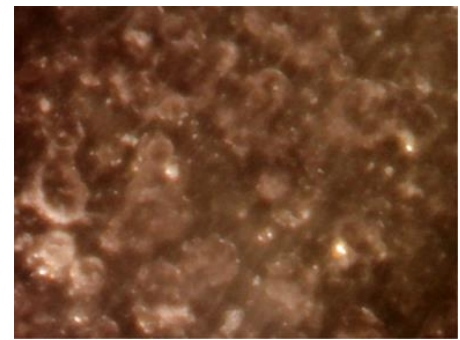

(b)

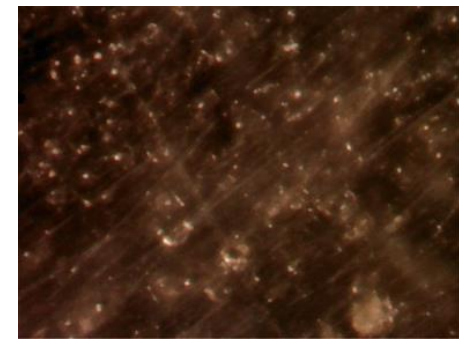

(c) 


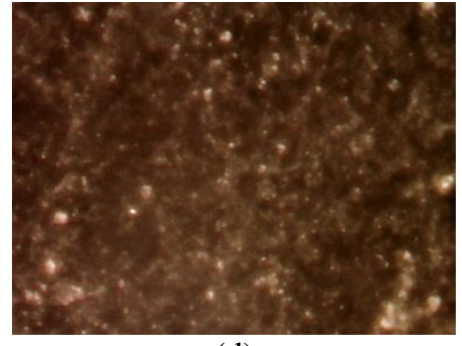

(d)

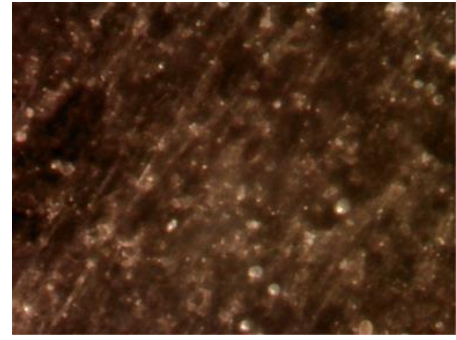

(e)

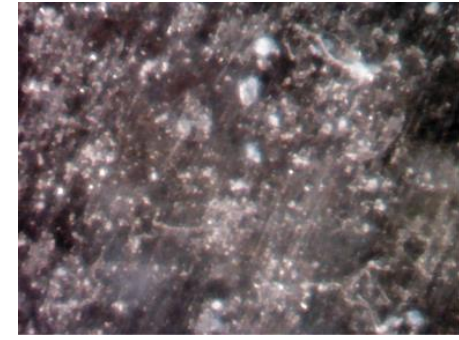

(f)

Gambar 1. Hasil dari baja yang sudah dielektrodeposisi dengan varisi tegangan dan penambahan inhibitor ektrak kulit buah kakao dengan konsentrasi $1 \%$

Hasil Pengamatan morfologi dengan mikroskop optik dengan perbesaran 100x dengan variasi tegangan $1 \mathrm{~V}, 2 \mathrm{~V}, 3 \mathrm{~V}, 4 \mathrm{~V}$ dan $5 \mathrm{~V}$ dan arus 2 $\mathrm{mA}$ dengan adanya penambahan dan tanpa adanya penambahan inhibitor ekstrak kulit buah kakao. Memperlihatkan permukaan baja yang belum dielektrodeposisi dan yang sudah dielektrodeposisi dengan variasi tegangan.

Dapat dilihat variasi tegangan yang digunakan adalah 1 volt sampai dengan 5 volt dengan adanya penambahan inhibitor ekstrak kulit buah kakao dengan konsentrasi 1\%. Pada Gambar 1a dapat dilihat hasil dari elektrodeposisi tanpa adanya penambahan inhibitor ekstrak kulit buah kakao, dapat dilihat permukaan tidak rapi dan ada banyak gumpalan, dan belum terlapisi semua permukaan baja. Pada Gambar 1b proses elektrodeposisi dengan variasi tegangan 1 volt dan adanya penambahan inhibitor ekstrak kulit buah kakao, terlihat sudah terlapisi dan banyak gumpalangumpalan tidak merata. Pada Gambar 1c dengan variasi tegangan 2 volt dapat dilihat belum merata, untuk variasi tegangan 3 vol dapat dilihat pada Gambar 1d, dilihat permukaann terlapisi secara merata dan lapisan terlihat tidak mengumpal dan terlapisi tipis. Sedangkan variasi tegangan 3 volt dan 4 volt terlihat permukaan merata tetapi tidak terlapisi dengan tipis dan terdapat banyak gumpalan.

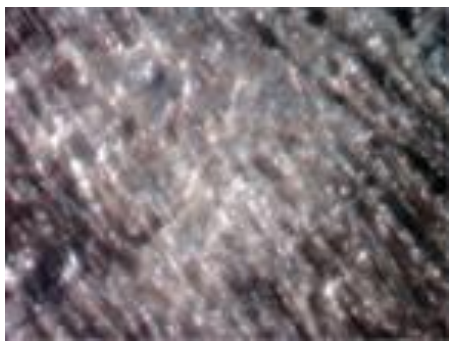

(a)

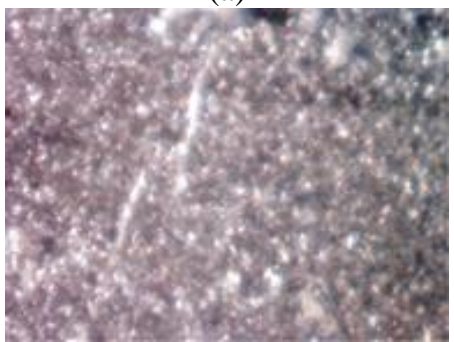

(d)

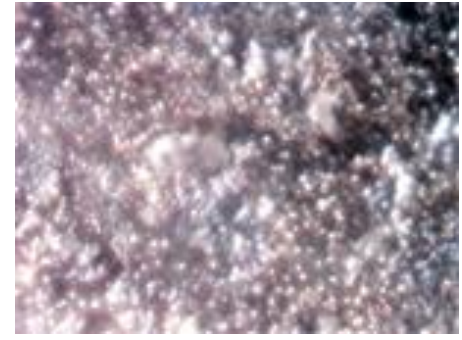

(b)

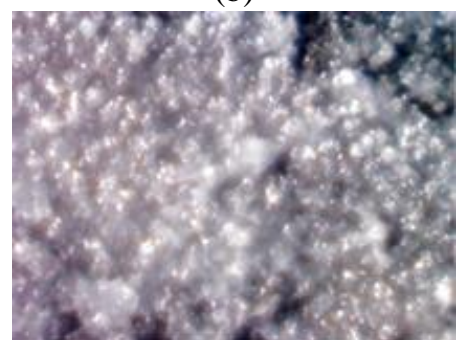

(e)

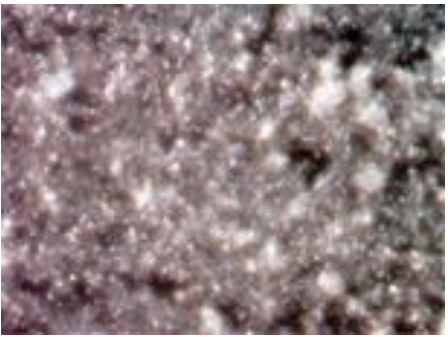

(c)

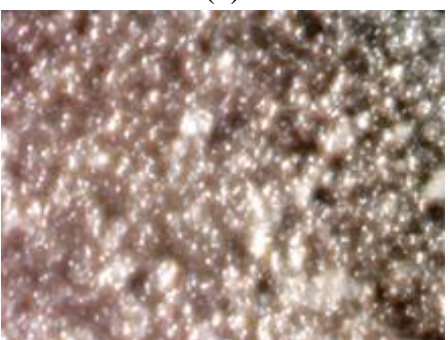

(f)

Gambar 2. Hasil dari baja yang sudah dielektrodeposisi dengan varisi tegangan dan penambahan inhibitor ektrak kulit buah kakao dengan konsentrasi $2 \%$.

Dapat dilihat variasi tegangan yang digunakan adalah 1 volt sampai dengan 5 volt dengan adanya penambahan inhibitor ekstrak kulit buah kakao dengan konsentrasi 2\%. Pada Gambar 2a dapat dilihat hasil dari elektrodeposisi tanpa adanya penambahan inhibitor ekstrak kulit buah kakao, dapat dilihat permukaan tidak rapi dan ada banyak gumpalan, dan belum terlapisi semua permukaan baja. Pada Gambar 2b proses elektrodeposisi dengan variasi tegangan 1 volt dan adanya penambahan inhibitor ekstrak kulit buah kakao, terlihat sudah terlapisi dan banyak gumpalangumpalan dan lapisan tebal. Pada Gambar 2c dengan variasi tegangan 2 volt dapat dilihat merata tetapi lapisan terlalu teba; untuk variasi tegangan 3 vol dapat dilihat pada Gambar 2d, dilihat permukaann terlapisi secara merata dan lapisan terlihat mengumpal dan lapisan tebal. Sedangkan 
variasi tegangan 3 volt dan 4 volt terlihat permukaan merata tetapi tidak terlapisi dengan tipis terlalu tebal dan terdapat banyak gumpalan.

\section{B. Scanning Electron Microscopy}

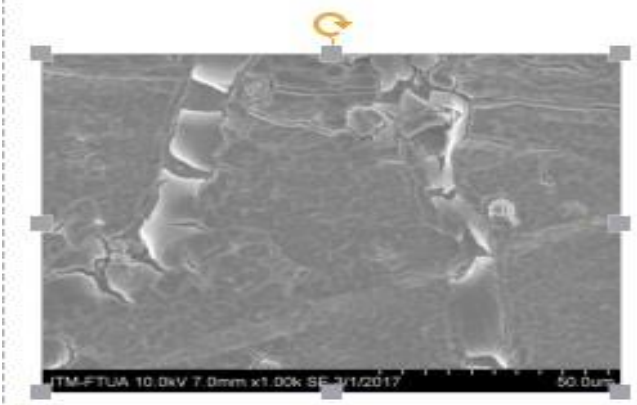

(a)

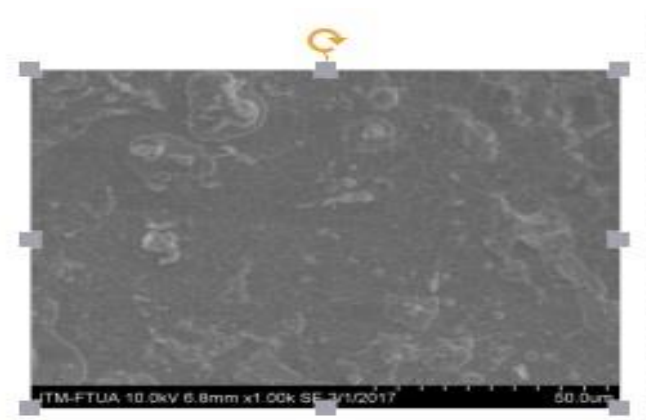

(b)

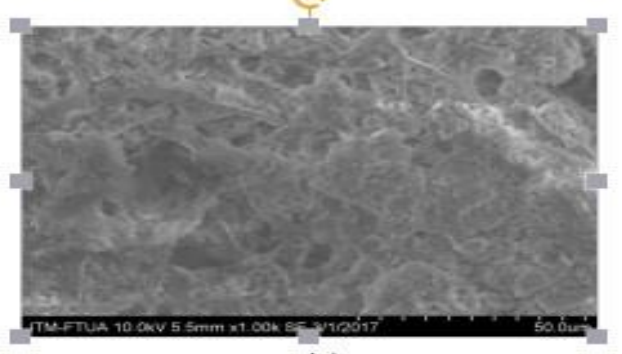

(c)

Gambar 3. Foto SEM dari baja yang sudah dielektrodeposisi dengan $\mathrm{NiSO}_{4}$ dan inhibitor ekstrak kulit buah kakao dengan perbesaran 1000x

Gambar 3 memperlihatkan hasil analisis morfologi permukaan baja dengan SEM pada perbesaran 1000x tanpa dan adanya inhibitor ekstrak kulit buah kakao. Pada Nikel tanpa penambahan inhibitor kulit buah kakao lapisan terlihat retakan yang cukup besar dan mudah terkelupas (Gambar 3a). Retakan lapisan tersebut memudahkan air atau bahan pelarut terperangkap ${ }^{[11]}$. Hal ini akan menyebabkan lapisan lebih mudah terkorosi ${ }^{[1,}$ 12, 13]. Elektrodeposisi larutan $\mathrm{NiSO}_{4}$ menggunakan inhibitor ekstrak kulit buah kakao $1 \%$ selama 25 menit ditunjukkan pada Gambar 3(b). Tampak bahwa lapisan permukaan yang dihasilkan lebih halus dari pada Gambar 3(a). Dengan demikian ekstrak kulit buah kakao mempengaruhi permukaan lapisan nikel. Gambar 3(c) memperlihatkan lapisan nikel yang dihasilkan dari penambahan inhibitor ekstrak kulit buah kakao $2 \%$. Permukaan lapisan banyak ditutupi oleh lapisan berbentuk putih, yang diduga sebagai pengaruh penambahan ekstrak kulit buah kakao

\section{DAFTAR PUSTAKA}

1. Yetri. Y., 2015, Inhibisi Korosi dan Pemulihan Sifat Mekanik Baja Lunak Menggunakan Ekstrak Kulit Buah Kakao ( Theobroma Cacao) Dalam Media Asam. Disertasi Program Doktor Ilmu Kimia, Fakultas MIPA, Universitas Andalas, Padang. yang berlebih, sehingga menutupi lapisan nikel itu sendiri. Hal ini juga terlihat saat terjadinya proses elektrodeposisi, dimana larutan tersebut agak keruh. Dari peristiwa ini dapat disimpulkan bahwa penambahan ekstrak kulit buah kakao yang berlebihan juga tidak bagus untuk sintesis lapisan nikel dengan metode elektrodeposisi

\section{KESIMPULAN}

Dari hasil elektrodeposisi dengan menggunakan larutan elektrolit $\mathrm{NiSO}_{4}$ dan adanya penambahan inhibitor ekstrak kulit buah kakao tegangan yang terbaik dalam melapisi permukaan baja ada dengan tegangan 3 volt, dan konsentrasi terbaik terdapat pada konsentrasi inhibitor ektrak kulit buah kakao $1 \%$ terlihat permukaan pelapisannya lebih merata dan lapisannya terlihat lebih tipis dan tidak adanya gumpalan-gumpalan pada permukaan baja.

2. Yuli. Y., 2016, Corrosion Behavior of Environmental Friendly Inhibitor of Theobroma cacao Peels Extract for Mild Steel in $\mathrm{NaCl} 1.5 \mathrm{M}$, Environmental Asia, Thai Society of Higher Education Institutes on Environment, 9(1), 45-59.

3. Figueira. A, and Janick, 2008, New Products from Theobroma cacao. Speed pulp and pod gum, Advances in Botanical Research, 55 hal. 885-892. 
4. Ekanem U.F, Umoren S.A, Udousoro S.A, and Udoh A.P, 2010, Inhibition of mild steel Corrosion in HCL using Pineapple leaves extract, Journal of Material Sciense, 45, hal. 5558-5566.

5. Agustina, E., Dahlan, D., Syukri., 2013, Struktur dan Sifat Optik Lapisan Tipis TiO2 (Titanium Dioksida) Yang Dihasilkan dengan Metode Elektrodeposisi, Jurnal Fisika Unand, Vol. 2, No. 3, Jurusan Fisika Unand, hal. 180185.

6. Ostovari A, Hoseinieh S.M, Peikari, M, Shadizadeh, S.R, and Hashemi.S.J. 2009. Corrosion Inhibitor of mild steel in $1 \mathrm{M} \mathrm{HCL}$ solution by Henna Extract : A Comparative Study of Inhibition by Henna and Its Contituents (Lawsone, Gallic acid, Glucose and Tanic acid). Corrosion Sciens, 51, hal. 1935-1949.

7. Loto, C.A, 2011, Inhibition effect of tea (Camellia Sinensis) extract on the corrosion of mild steel in dilute sulphuric acid, J.Mater. Environ Sciens 2(4), hal. 335-344.

8. Mustopo, D.Y., 2011, Pengaruh Waktu Terhadap Ketebalan dan Adhesivitas Lapisan pada Proses Elektroplating Khrom Dekoratif Tanpa Lapisan Dasar, dengan Lapisan Dasar
Tembaga dan Tembaga-Nikel, Skripsi, Teknik Mesin Fakultas Teknik, Universitas Sebelas Maret, Surakarta.

9. Mustopo, D.Y., 2011, Pengaruh Waktu Terhadap Ketebalan dan Adhesivitas Lapisan pada Proses Elektroplating Khrom Dekoratif Tanpa Lapisan Dasar, dengan Lapisan Dasar Tembaga dan Tembaga-Nikel, Skripsi, Teknik Mesin Fakultas Teknik, Universitas Sebelas Maret, Surakarta.

10. Purnomo, A., 2015, pengaruh variasi konsentrasi inhibitor ekstrak kulit buah kakao terhadap laju korosi pipa baja karbon a53 pada media air laut, Jurnal ROTOR, Volume8 Nomor1, Jur. Teknik Mesin, Universitas Jember, Hal. 8-12.

11. Yatiman.P., 2009, Application of Organic Inhibitors for Corrosion Control of Metals and Alloys, Prosiding Seminar Nasional Penelitian, Pendidikan dan Penerapan MIPA, Fakultas MIPA, Universitas Negeri Yogyakarta, Yogyakarta.

12. Dahlan, D., 2009, Electrodeposition of $\mathrm{Cu} 2 \mathrm{O}$ Particles by Using Electrolyte Solution Containing Glucopone as Surfactant, Jurnal Ilmiah Fisika (JIF), Vol. 1, No. 2, Jur. Fisika Unand, hal. 18-20. 